\title{
INTERVENCIÓN DEL PROFESOR MARCOS GARCÍA DE LA HUERTA
}

La concesión de la Orden Gabriela Mistral a Patrice Vermeren es un acto de reconocimiento oficial a un trabajo de colaboración con las universidades chilenas, que se extiende ya por varias décadas. Significa también honrar una trayectoria; y es un motivo especial de alegría, que sea nuestra embajadora, señora Marcia Covarrubias, quien haya tenido la sensibilidad e inteligencia para apreciar el significado y valor excepcional de lo que ha hecho Patrice por las humanidades y por la filosofía en Chile. Por eso, espero que muy pronto la Universidad de Chile se sume a este reconocimiento; Patrice ha dedicado gran parte de su vida profesional y familiar -Susana Villavicencio, su mujer, es argentina- a la relación con América Latina y con Chile en particular: fuimos,en cierto modo, pioneros en esta colaboración y hemos sido también afortunados de contar con interlocutores de la calidad personal e intelectual de Patrice, de Stephane Douahier, Etienne Tassin, George Navet, Bertrand Ogilvie y Jacques Poulin, entre otros. Tenemos que lamentar ahora la partida definitiva de Etienne Tassin, atropellado no muy lejos de aquí, en el puente Alejandro III, hace apenas unas semanas; con él compartimos también momentos inolvidables en coloquios en Valparaíso, Buenos Aires, Paris y en Bogotá, donde convivimos una semana con Etienne y Xabier Insausti. Su partida repentina, prematura, intempestiva, la sentimos como una pérdida irreparable.

El Collège International de Philosophie es la otra institución que ha sido nuestra contraparte acá. El plural viene a cuento, porque con Carlos Ruiz, Humberto Giannini, Carlos Ossandón, Cecilia Sánchez, entre otros, hemos bregado con Patrice y su grupo en estos ya largos años de labor conjunta. A él no le va gustar que lo asocien a instituciones, aunque él mismo se ha convertido en un referente obligado en estos intercambios. El propio Collège International, que él creó junto con Jacques Derrida y otros filósofos, surgió como un margen de la institución, un borde desde donde fuesen posibles, justamente, iniciativas heréticas como esta, que sacuden inercias institucionales y hacen posible una cooperación libre, sostenida en el pensamiento y crecida en la amistad.

El vínculo con Paris 8 comenzó en plena dictadura, a través de la Academia de Humanismo Cristiano, que cobijó a toda una generación de intelectuales valiosos, que no encontraban cabida en un sistema universitario intervenido. Una vez recobrada la institucionalidad democrática, la relación se mantuvo, extendida a varias otras universidades, en gran parte gracias al empuje y tenacidad de Patrice. Esa obstinación es lo que ha permitido, por otra parte, que haya podido venir y compartir este acto con ustedes, cuando todo conspiraba en contra: Paris bajo la nieve, cortes de energía, dificultades de transporte, la Universidad paralizada en toma, en fin, las trabas burocráticas de rigor. Patrice se sobrepone a toda adversidad e invoca, por todo comentario, una palabra de Spinoza: "perseverar en su ser". 
Quisiera contarles, muy brevemente, algo de lo que hemos realizado en estos años, especialmente en la colaboración con la Universidad de Chile. Ustedes han podido apreciar en las presentaciones anteriores, que la labor de Patrice se extiende a través de una red de universidades, así que me limitaré a dar testimonio de lo que ha sido su relación con la Universidad de la que puedo hablar con más propiedad y de nuestra colaboración con la Universidad de Paris 8.

Destaco aquí lo siguiente:

1. La creación de un programa de doctorado en filosofía conjunto entre la Universidad de Paris 8 y la Universidad de Chile. Este grado académico es válido tanto en Chile como en Francia.

2. La creación de un sistema de intercambio que ha permitido la visita de destacados investigadores franceses a Chile y de chilenos a Francia; se han dictado numerosos cursos, conferencias y seminarios en el marco de este programa.

3. En 1990, por iniciativa y gracias a la gestión de Patrice, se envió a Chile un avión con libros. Una remesa de esa envergadura nunca antes había llegado a Chile, salvo, quizá, cuando se creó la Biblioteca Central de la Universidad de Chile, bajo el rectorado de Andrés Bello.

4. La organización de numerosos congresos, coloquios y seminarios internacionales, realizados inicialmente en Paris, Santiago y Valparaíso. De estos encuentros surgieron publicaciones conjuntas, monografías, artículos en revistas y traducciones. Entre estas, recuerdo ahora la del libro de Giannini sobre la vida cotidiana, el de Cecilia Sánchez sobre el cuerpo femenino, uno mío - Crítica de la razón tecnocrática-y otro conjunto sobre política y cultura en América Latina. Todos aparecieron en una colección de L'Harmatann cuyo nombre nos interpreta muy bien: La philosophie en commun. Antes de venir, tuve entre mis manos un libro editado por Patrice junto con Claudia Gutiérrez y Carlos Ruiz, sobre democracia y emancipación.

5. Entre los congresos, recuerdo el de 1992 en conmemoración de los 500 años del Descubrimiento, y que dio lugar a la discusión de asuntos que han adquirido cada vez mayor relevancia y actualidad, como la mundialización, las migraciones, el choque de culturas y la cuestión de las minorías, entre otros.

Con motivo de la celebración del bicentenario, en 2010, realizamos otros dos Congresos Internacionales, en Santiago y en Paris. Los temas centrales fueron, naturalmente, la república, la cuestión de la fundación de los Estados. Recuerdo que Patrice cuestionó la figura del héroe y la emancipación como obra de una singularidad excepcional, como la concebía Maquiavelo, y sugirió más bien un heroísmo asociado a la acción común del pueblo soberano. Otro gran tema del mismo Congreso fue el del estatuto historial de las naciones de la América Meridional. Los Estados del Nuevo Mundo consiguieron su independencia con la conducción de sus propias poblaciones europeas. Para bien o para mal, fueron los colonizadores los que decidieron romper el lazo político con la metrópolis imperial. Eso hace una diferencia categorial con los países"post coloniales" que surgieron 
en África, parte de Asia y Medio Oriente. Y la recuperación de la democracia ¿no era la parodia de ese pasado que parece no pasar y sigue pasando? Independizarse de una monarquía y liberarse de una dictadura tienen cierto parecido de familia: instauran la política abatiendo una autocracia que la hacía imposible.

A Patrice le gusta decir que su contacto con Latinoamérica contribuyó a redefinir su vida; somos varios los que podemos parafrasearlo. El vínculo con Francia significó abrir espacios de libertad fuera de la"universidad vigilada", como la llamó Jorge Millas. Aprendimos en carne propia, que el pensamiento vigilado es enemigo de la vigilia del pensamiento. Si miramos ahora ese comienzo, vemos que fue el inicio de algo permanente y que nuestras vidas se definieron en buena medida por esa permanencia, gracias a ella, y habrían sido, sin duda, otras y distintas sin ella.

La pregunta ahora es: ¿seremos capaces de mantener la orientación y fuerza del comienzo?

Es una cuestión que permanece como pregunta, pero ya hemos visto en nuestros recientes encuentros los rostros del recambio. De seguro, este reconocimiento con la Orden de la insigne poetisa, será un estímulo y un nuevo impulso para otros comienzos, que honren el lema tantas veces invocado -"perseverar en su ser". 